\title{
Effect of Simultaneous Inhibition of Protein Kinase CK2 and Thymidylate Synthase in Leukemia and Breast Cancer Cells
}

\author{
PATRYCJA WIŃSKA ${ }^{1}$, KATARZYNA SKIERKA ${ }^{1}$, EDYTA ŁUKOWSKA-CHOJNACKA ${ }^{1}$, \\ MIROSŁAWA KORONKIEWICZ ${ }^{2}$, JOANNA CIEŚLA ${ }^{1}$ and MARIA BRETNER ${ }^{1}$ \\ ${ }^{1}$ Chair of Drug and Cosmetics Biotechnology, Faculty of Chemistry, \\ Warsaw University of Technology, Warsaw, Poland; \\ ${ }^{2}$ Department of Drug Biotechnology and Bioinformatics, National Medicines Institute, Warsaw, Poland
}

\begin{abstract}
Background/Aim: Protein kinase CK2 was recently identified as a promising therapeutic target for combination therapy. Our study aims to investigate the anticancer effect of a simultaneous inhibition of thymidylate synthase (TS) and CK2 in MCF-7 breast cancer and CCRFCEM leukemia cells. Materials and Methods: The type of interaction between CK2 inhibitors: CX-4945, 4,5,6,7tetrabromo-1H-benzimidazole (TBBi), or recently obtained 4,5,6,7-tetrabromo-2-methyl- $1 \mathrm{H}$-benzimidazol- 1 $y l$ )acetonitrile (2b) and TS-directed anticancer drug, 5fluorouracil (5-FU) was determined using the MTT assay and a combination index method. The influence of the combined treatment on apoptosis in leukemia cells, as well as on cell-cycle progression and the levels of TS, CK2 $\alpha$ and $P$-Ser529-p65 were determined in both cell lines, using flow cytometry and western blot analysis, respectively. Results: The best synergistic effect was observed in CCRF-CEM cell line with the combination of 5-FU and $2 b$ which correlated with a decrease in the endocellular CK2 activity and enhancement of the pro-apoptotic effect. Conclusion: The obtained results demonstrate the ability of $C K 2$ inhibitors to enhance the efficacy of 5-FU in anticancer treatment, indicating a different molecular mechanism of the studied CK2 inhibitors interaction with 5-FU.
\end{abstract}

Inhibition of protein kinase CK2 by small ATP-competitive inhibitors like 4,5,6,7-tetrabromo- $1 H$-benzimidazole (TBBi) and its derivatives, or by clinical stage agent CX-4945 (Silmitasertib) in breast cancer cell lines caused a range of

Correspondence to: Patrycja Wińska, Chair of Drug and Cosmetics Biotechnology, Faculty of Chemistry, Warsaw University of Technology, Noakowskiego St. 3, 00-664, Warsaw, Poland. Tel: +48 222345573, e-mail: pwinska@ch.pw.edu.pl

Key Words: Synergism, protein kinase CK2, thymidylate synthase, 5-fluorouracil, CX-4945, 4,5,6,7-tetrabromo- $1 \mathrm{H}$-benzimidazole. phenotypic changes in these cell lines, including decreased viability, cell cycle arrest, apoptosis and loss of migratory capacity $(1,2)$. It was demonstrated that inhibition of CK2 by CX-4945 activated caspase- 3 and caspase-7 in cancer cells with no detectable change of caspase-3/7 activity in normal cells and caused arrest in $\mathrm{G}_{2}-\mathrm{M}$ transition in breast cancer cells (2). The efficacy of CX-4945 has also been evaluated in a broad range of human hematologic cancers, including chronic lymphocytic leukemia (CLL), T-cell acute lymphocytic leukemia (ALL), acute myeloid leukemia (AML), and lymphomas (3-5). Moreover, it has been demonstrated (6, 7) that anti-proliferative activity of CX-4945 against chronic lymphocytic leukemia (CLL) was higher when used in a combination with several other inhibitors, including GS-1101, ibrutinib, and fludarabine, regulating B-cell receptor (BCR)mediated signaling cascades or downstream mediators. It has been shown that the anti-proliferative effect of CK2 inhibition was caused by suppressed activation of CK2-mediated $\mathrm{PI} 3 \mathrm{~K} / \mathrm{Akt} / \mathrm{mTOR}$ signaling pathways that act downstream of BCR (8). Additionally, it was demonstrated that bortezomib (proteasome inhibitor)/CX-4945 combined treatment induced synergistic apoptotic effects in T- and B-ALL cell lines, via reduction of chaperoning activity of Hsp90 (9) and inhibition of NF-kB signaling in T-ALL cell lines as well as in primary cells from T-ALL patients. Recently, it has also been shown that T-ALL cells express high levels of CK2 subunits, and that CK2 inhibition by CX-4945 had synergistic effects promoting the inhibition of survival and IL-2 production in T-ALL cells (10). Other studies demonstrated that simultaneous treatment of A2780 and SKOV-3 ovarian cancer cells with CX-4945 and cisplatin or gemcitabine promotes synergistic induction of apoptosis. This synergistic effect was a result of inactivation of XRCC1 and MDC1, two mediator/adaptor proteins essential for DNA repair (11).

Recently, it has been reported that protein kinase CK2 phosphorylates in vitro human thymidylate synthase (TS) (12, 13) a key enzyme of a thymidylate biosynthesis cycle that catalyzes the conversion of dUMP to dTMP, which 
subsequently undergoes phosphorylation to dTTP, a substrate for DNA polymerases. CK2 mediated phosphorylation of TS stabilizes it in an inactive conformation (13). Additionally, another study proved that the phosphorylated recombinant TS forms show decreased (at least by 3 -fold) molecular activity, compared to the non-phosphorylated forms, and bind their cognate mRNA repressing their own mRNA translation (14). As inhibition of TS leads to the cessation of DNA replication and thymineless death of proliferating cells, the enzyme is an attractive target for cancer chemotherapy (15). 5-Fluorouracil (5-FU) is one of the most commonly used TS-directed anticancer drug applied in combination with other chemotherapy compounds for treatment of various cancers (16-19). 5-FU is converted inside cells into 5-fluoro-dUMP (F-dUMP), which forms stable complex with TS and thus inhibits deoxythymidine monophosphate (dTMP) production, essential for DNA replication and repair (20). Another important mechanism of 5-FU-induced cytotoxicity is its misincorporation into RNA and DNA in place of uracil or thymine, that consequently induces DNA repair and finally double strand breaks (DSB) induction and DNA damage (21).

Based on the assumptions, that CK2 inhibitors may influence the endocellular activity and protein level of TS, as well as inhibition of TS consequently leads to DNA damage (22), which can be repaired with the participation of CK2 (23), we have hypothesized that simultaneous inhibition of CK2 and TS may lead to a synergistic effect in anticancer therapy. Therefore, the aim of our studies was the investigation of the treatment of two cancer cell types, acute lymphoblastic leukemia (CCRF-CEM) and breast cancer (MCF-7), with compound combinations using 5-FU together with different inhibitors of protein kinase CK2: CX-4945, TBBi, or its previously obtained derivative (4,5,6,7-tetrabromo-2-methyl$1 H$-benzimidazol-1-yl)acetonitrile (2b) (1). We have previously shown that a new inhibitor of CK2 $\alpha(4,5,6,7-$ tetrabromo-2-methyl-1H-benzimidazol-1-yl)acetonitrile (2b) $(\mathrm{Ki}=1.63 \mu \mathrm{M})$ demonstrated significantly better anticancer properties toward CCRF-CEM and MCF-7 cells, than the parental compound, TBBi (1). Additionally, the newly obtained derivative $2 \mathrm{~b}$ induced endocellular CK2 inhibition in a higher extent than TBBi in both CCRF-CEM and MCF-7 cell lines and demonstrated better pro-apoptotic activity towards leukemia cells ( $\sim 7 \%$ apoptotic cells at $10 \mu \mathrm{M} 2 \mathrm{~b}$ ), than TBBi (5.1\% apoptotic cells at $10 \mu \mathrm{M}$ TBBi).

To evaluate the combination effect, we sought to determine CI (combination index values) for each compound combination. Our results show, that synergistic effect occurs in CCRF-CEM only with the combination of 5-FU with $2 \mathrm{~b}$, whereas in MCF-7 only with the combination of 5-FU with CX-4945. To explain the mechanism of the observed synergistic effect, the influence of the above mentioned combinations on pro-apoptotic properties, cell cycle progression, CK2 inhibition (phosphorylation extent of
Ser529 p65), TS and CK $2 \alpha$ protein level was studied. Our results show, that the combination of $2 \mathrm{~b}$ and $5-\mathrm{FU}$ synergistically enhances inhibition of CK2 in CCRF-CEM, leading to increased apoptosis, while a synergistic effect observed in MCF-7 cells after treatment with the combination of 5-FU and CX-4945 can be due to the delay of 5-FU-induced S-phase arrest recovery.

\section{Materials and Methods}

Reagents and antibodies. Dimethyl sulphoxide (DMSO), Molecular Biology grade, used as a solvent for all stocks of the chemical agents, was obtained from Roth (Karlsruhe, Germany). All reagents used in flow cytometry were purchased from BD Biosciences Pharmingen (San Diego, CA, USA). Primary polyclonal antibodies against PSer529-p65, monoclonal antibodies against TS and CK2 $\alpha$ were purchased from Santa Cruz Biotechnology (Santa Cruz, CA, USA), whereas polyclonal antibodies against total p65 and monoclonal GAPDH antibodies were from Cell Signalling Technology (Beverly, MA, USA), and Merck Millipore (Darmstadt, Germany), respectively. Secondary goat anti-rabbit IgG-HRP and anti-mouse IgG were purchased from DAKO (Santa Clara, CA, USA). Protease inhibitors were from Bioshop. Nitrocellulose membrane was from GE Healthcare Life Sciences (Freiburg, Germany), solvents for HRP reaction (Western Bright Peroxide and Western Bright Quantum) were purchased from Advansta. CX-4945 was obtained from Biorbyt. TBBi and its derivative $-2 b$, were obtained as it was described previously (1). Other solvents, reagents and chemicals were purchased from POCH (Avantor Performance Materials, Gliwice, Poland) Merck and Sigma-Aldrich Chemical Company (St. Louis, MO, USA).

Cell culture and treatment with agents. MCF-7 adherent cells (human breast cancer cell line) were cultured in DMEM with high glucose medium (Lonza, Basel, Switzerland) supplemented with $10 \%$ fetal bovine serum (EuroClone), $2 \mathrm{mM} \mathrm{L}$-glutamine, antibiotics (100 U/ml penicillin, $100 \mu \mathrm{g} / \mathrm{ml}$ streptomycin) and $10 \mu \mathrm{g} / \mathrm{ml} \mathrm{of}$ human recombinant insulin. CCRF-CEM suspension cells were cultured in RPMI 1640 medium (Lonza) supplemented with 10\% fetal bovine serum (EuroClone) and antibiotics $(100 \mathrm{U} / \mathrm{ml}$ penicillin, $100 \mu \mathrm{g} / \mathrm{ml}$ streptomycin). Cells were grown in $75 \mathrm{~cm}^{2}$ cell culture flasks (Sarstedt, Nümbrecht, Germany), in a humidified atmosphere of $\mathrm{CO}_{2} /$ air $(5 / 95 \%)$ at $37^{\circ} \mathrm{C}$.

All the experiments were performed in exponentially growing cultures. Stock solutions of the tested compounds were prepared in DMSO and stored in $-80^{\circ} \mathrm{C}$ for maximum one month. For the cytotoxicity studies, stock solutions of the tested compounds were diluted 400 -fold with the proper culture medium to obtain the final concentrations. Stock solutions were diluted in a 1:1 ratio with DMSO or the second compound for a single compound and combination tests, respectively, so the final concentration of vehicle was constant in each case, and the same stock solution was used in each experiment. For cytotoxicity studies 2-fold serial dilutions were prepared in the proper medium containing $0.5 \%$ DMSO.

MTT-based viability assay. Before treatment MCF-7 cells were trypsinized in $0.25 \%$ trypsin-EDTA solution (Sigma-Aldrich) and seeded into 96-well microplates (Sarstedt) at a density of $1.5-3 \times 10^{4}$ cells/well. Cells were treated with the tested compounds or DMSO $(0.5 \%)$ at the appropriate concentrations $18 \mathrm{~h}$ after plating. CCRF- 
CEM were seeded at $4 \times 10^{4}$ cells/well and treated with the compounds. After $72 \mathrm{~h}$ incubation, leukemia cells were centrifuged and supernatants of CCRF-CEM and MCF-7 cells were discarded; subsequently MTT stock solution (Sigma-Aldrich) was added to each well to the final concentration of $0.5 \mathrm{mg} / \mathrm{ml}$. After $2 \mathrm{~h}$ incubation at $37^{\circ} \mathrm{C}$, water-insoluble dark blue formazan crystals were dissolved in DMSO $(200 \mu \mathrm{l})\left(37^{\circ} \mathrm{C} / 10 \mathrm{~min}\right.$ incubation). Optical densities were measured at $570 \mathrm{~nm}$ using BioTek microplate reader. All measurements were carried out in a minimum of six replicates and the results expressed as fraction of not viable cells $(\mathrm{Fa})$ relative to control (cells without inhibitor in 0.5\% DMSO). Fa values were calculated from the following equation 1-(T-B/C-B), where $\mathrm{T}$ and $\mathrm{C}$ mean absorbance obtained for the treated and untreated cells, respectively, whereas B means blank well (without cells).

Detection of apoptosis. CCRF-CEM cells were cultured in 6-well plates in a density of $1.8 \times 10^{5} / \mathrm{ml}$ and treated with the tested compounds as it was described above. Then, the cells were harvested by centrifugation at $200 \times g$ at $4^{\circ} \mathrm{C} / 5 \mathrm{~min}$, washed twice in cold PBS, and subsequently suspended in binding buffer at $1 \times 10^{6}$ cells $/ \mathrm{ml}$. Then, 100- $\mu \mathrm{l}$ aliquots of the cell suspension were labeled according to the kit manufacturer's instructions. Briefly, annexin VFITC and PI (BD Pharmingen) were added to the cell suspension, and the mixture was vortexed and incubated for $15 \mathrm{~min}$ at room temperature in the dark. Then, $400 \mu$ of cold binding buffer was added, and the cells were vortexed again and kept on ice. Flow cytometry measurements were performed within $1 \mathrm{~h}$ after labeling. Viable, necrotic, early and late apoptotic cells were detected by flow cytometry using BD FACSCanto II and analyzed with a BD FACSDiva software.

Cell cycle analysis. The MCF-7 and CCRF-CEM cells were cultured in $25 \mathrm{~cm} 2$ culture flasks and treated with the tested compounds as it was described above. After exposure to the tested compounds, the cells were washed with cold PBS and fixed at $-20^{\circ} \mathrm{C}$ in $70 \%$ ethanol for at least $24 \mathrm{~h}$. Subsequently, the cells were then washed in PBS and stained with $50 \mu \mathrm{g} / \mathrm{ml}$ PI and $100 \mu \mathrm{g} / \mathrm{ml}$ RNase solution in PBS supplemented with $0.1 \%$ v/v Triton X-100 for $30 \mathrm{~min}$ in the dark at room temperature. Cellular DNA content and the distribution of the cells in different phases of the cell cycle were determined by flow cytometry employing FACS Canto II flow cytometer (BD Biosciences, San Jose, CA, USA), and analyzed using the BD FACSDiva software. The obtained DNA histograms were analyzed using the MacCycle (Phoenix Flow Systems, San Diego, CA, USA) software.

Western blotting. The CCRF-CEM cells growing exponentially were seeded at $2 \times 10^{5}$ cells $/ \mathrm{ml}$ in $75 \mathrm{~cm}^{2}$ flasks. Subsequently compounds were added in a final concentration of $0.5 \%$ DMSO. After $48 \mathrm{~h}$ treatment, cells were centrifuged $\left(200 \times g, 1,700 \mathrm{rpm}, 4^{\circ} \mathrm{C}\right.$ for $5 \mathrm{~min}$ ), washed $(3 \times$ with PBS), and pellets were collected and stored at $-20^{\circ} \mathrm{C}$. For the assay, cells were lysed in RIPA buffer (50 $\mathrm{mM}$ Tris- $\mathrm{HCl} \mathrm{pH} 7.4,1 \% \mathrm{NP}-40,0.5 \%$ sodium deoxycholate, $0.1 \%$ SDS, $150 \mathrm{mM} \mathrm{NaCl}, 2 \mathrm{mM}$ EDTA, $50 \mathrm{mM} \mathrm{NaF}, 0.2 \mathrm{mM}$ sodium orthovanadate and Protease Inhibitors Cocktail, Roche). The protein concentration was determined using Bradford assay. Equivalent amounts of total protein $(40 \mu \mathrm{g})$ were analyzed by SDS-PAGE and subsequently western blotting was performed using P-Ser529-p65 (1:500 dilution), total p65 $(1: 1,000)$, TS $(1: 1,000)$, CK2 $\alpha(1: 500)$ and GAPDH (1:500 dilution) primary antibodies in Blocking
Buffer: 3\% BSA in TBST (10 mM Tris- $\mathrm{HCl}$ pH 8, $150 \mathrm{mM} \mathrm{NaCl}$, $0.1 \%$ Tween 20). After overnight incubation at $4^{\circ} \mathrm{C}$ with the primary antibodies, the membranes were washed with TBST and subsequently the secondary goat anti-rabbit IgG-HRP or anti-mouse Ig-HRP antibodies were used at 1:5,000 dilution. ECL substrate (Biorad) was used for detection and immunoblots were scanned using G Box Chemi (Syngene).

Densitometry. For densitometry, immunoblots were scanned using G Box Chemi (Syngene), and the density of each lane of phosphorylated and total protein was quantified, using Image $\mathbf{J}$ software. Phosphorylated protein densities were normalized to GAPDH densities, assuming $100 \%$ for untreated cells and then they were converted to a percent of the appropriate control.

\section{Results}

Two cell lines, CCRF-CEM and MCF-7, representing acute lymphoblastic leukemia (ALL) and breast cancer, respectively, were treated with the combinations of selected inhibitors of CK2 and TS. CX-4945, TBBi, 4,5,6,7tetrabromo-2-methyl-1 $H$-benzimidazol-1-yl)acetonitrile (2b), and 5-FU were used, respectively. Among these compounds CX-4945 is in stage I/II clinical trial, TBBi is established as a strong CK2 inhibitor, 5-FU is a well-known prodrug targeting TS, and 2b was recently synthesized (1) as a new compound which efficiently induced inhibition of CK2 in both CCRF-CEM and MCF-7 and demonstrated better anticancer properties against MCF-7 than TBBi. MTT-based assay and the combination index method (24) were used to determine the type of interaction (i.e., synergistic, additive or antagonistic) between one of the CK2 inhibitors: TBBi, $2 \mathrm{~b}$ or CX-4945 and 5-FU (inhibition of TS by 5-FU metabolite, FdUMP). Additionally, the dose reduction index (DRI) was determined on the basis of drug interaction data analysis. This parameter is inversely associated with $\mathrm{CI}$ and represents the number of times each single drug dose may be reduced in a combination setting without compromising the final therapeutic effect (24). To understand the mechanism of a synergistic interaction, the influence of selected compound combinations on cell cycle progression, apoptosis and cellular level of TS and CK $2 \alpha$ proteins as well as on activity of CK2 (phosphorylation extent of Ser529 p65) were investigated.

Influence of compounds on viability of cancer cell lines. To optimize the compounds ratio used in the combination treatment, the influence on the cell viability of each compound used alone, and the shape of the dose effect curve were determined by obtaining $\mathrm{Dm}$ values and $\mathrm{m}$ parameter, respectively. The results are summarized in Table I. Interestingly, the obtained Dm values (with the exception of 5-FU) were mostly higher for breast cancer cells (6.41-19.27 $\mu \mathrm{M})$, than for leukemia cells $(2.54-8.27 \mu \mathrm{M})$. The TBBi derivative $2 \mathrm{~b}$ was more effective (Dm 2.54-6.41 $\mu \mathrm{M}$ ), than $\mathrm{CX}$ - 
Table I. The drug potency $(\mathrm{Dm})$ and steepness $(\mathrm{m})$ of the dose-response curves obtained after fitting the MTT-based assay data to the median effect equation using CalcuSyn Software.

\begin{tabular}{|c|c|c|c|c|c|}
\hline \multirow[t]{2}{*}{ Compound } & \multirow{2}{*}{$\begin{array}{l}\text { Molecular } \\
\text { target }\end{array}$} & \multicolumn{2}{|c|}{ CCRF-CEM } & \multicolumn{2}{|c|}{ MCF-7 } \\
\hline & & $\mathrm{Dm}^{*} \pm \mathrm{SD}(\mu \mathrm{M})$ & $\mathrm{m}^{* *} \pm \mathrm{SD}$ & $\mathrm{Dm} \pm \mathrm{SD}(\mu \mathrm{M})$ & $\mathrm{m} \pm \mathrm{SD}$ \\
\hline 4,5,6,7-tetrabromo- $1 H$-benzimidazole (TBBi) & CK2 & $11.29 \pm 0.57$ & $8.50 \pm 2.26$ & $19.27 \pm 2.69$ & $1.68 \pm 0.24$ \\
\hline (4,5,6,7-tetrabromo-2-methyl- $1 H$-benzimidazol-1-yl)acetonitrile (2b) & CK2 & $2.54 \pm 0.34$ & $3.95 \pm 1.86$ & $6.41 \pm 0.63$ & $2.66 \pm 1.38$ \\
\hline CX-4945 (Silmitasertib) & CK2 & $3.09 \pm 0.50$ & $3.43 \pm 0.42$ & $8.36 \pm 0.35$ & $1.12 \pm 0.18$ \\
\hline 5-Fluorouracil (5-FU) & TS & $120 \pm 13.86$ & $3.06 \pm 1.16$ & $14.88 \pm 2.56$ & $0.74 \pm 0.05$ \\
\hline
\end{tabular}

*Dm: Values were obtained after fitting the MTT-based assay data to median effect equation using the CalcuSyn software. **m: The slope of the median-effect plot.

Table II. Combination index values calculated at $E D_{50}, E D_{75}$ and $E D_{90}$, Dm and DRI values for tested drug combinations at constant ratio for CCRF-CEM and MCF-7 after $72 \mathrm{~h}$ treatment.

\begin{tabular}{|c|c|c|c|c|c|c|c|c|c|c|c|}
\hline \multirow{3}{*}{$\begin{array}{l}\text { Drugs in } \\
\text { combination }\end{array}$} & \multirow{3}{*}{$\begin{array}{c}\text { Combination } \\
\text { ratio* }\end{array}$} & \multicolumn{3}{|c|}{ CCRF-CEM } & \multirow{3}{*}{$\mathrm{Dm}$} & \multirow{3}{*}{$\begin{array}{l}\text { DRI for } 5-\mathrm{FU} \\
\text { at } \mathrm{Fa}=0.95\end{array}$} & \multirow{2}{*}{\multicolumn{3}{|c|}{ Combination Index at }} & \multirow{3}{*}{\multicolumn{2}{|c|}{ DRI for $5-\mathrm{FU}$}} \\
\hline & & \multicolumn{3}{|c|}{ Combination Index $* *$ at } & & & & & & & \\
\hline & & $\mathrm{ED}_{50}$ & $\mathrm{ED}_{75}$ & $\mathrm{ED}_{90}$ & & & $\mathrm{ED}_{50}$ & $\mathrm{ED}_{75}$ & $\mathrm{ED}_{90}$ & & \\
\hline 5-FU:CX-4945 & $12: 1$ & $1.79 \pm 0.12$ & $1.69 \pm 0.40$ & $1.64 \pm 0.40$ & $35.94 \pm 22.36$ & $612.25 \pm 5.79$ & $0.92 \pm 0.11$ & $0.74 \pm 0.07$ & $0.62 \pm 0.08$ & $11.31 \pm 3.68$ & $3.25 \pm 0.01$ \\
\hline 5-FU:TBBi & $6: 1$ & $1.18 \pm 0.15$ & $1.18 \pm 0.06$ & $1.20 \pm 0.04$ & $56.44 \pm 4.91$ & $6.57 \pm 4.23$ & $1.56 \pm 0.11$ & $1.08 \pm 0.37$ & $1.83 \pm 0.8$ & $25.06 \pm 13.37$ & $7 \quad 1.54 \pm 0.51$ \\
\hline 5-FU: 2b & $12: 1$ & $0.81 \pm 0.19$ & $0.65 \pm 0.19$ & $0.52 \pm 0.18$ & $13.27 \pm 5.78$ & $20.60 \pm 5.67$ & $1.00 \pm 0.11$ & $1.57 \pm 0.25$ & $1.32 \pm 0.29$ & $10.24 \pm 0.03$ & $4.65 \pm 2.21$ \\
\hline
\end{tabular}

*The combination ratios depended on previously obtained Dm for each tested drug alone; six to eight data points at 2-fold dilution range were used for each combination. $* * \mathrm{CI}$ values were generated by CalcuSyn software after fitting Fa values obtained by MTT-based assay.

4945 (Dm 3.09-8.36 $\mu \mathrm{M})$. For leukemia cells, all tested compounds showed sigmoidal dose effect curves $(m>1)$, whereas for MCF-7, sigmoidal curves were obtained only for TBBi and 2b, while for CX-4945 and 5-FU dose-effect curves were hyperbolic $(m=1)$ and flat sigmoidal $(m<1)$, respectively.

\section{Compound combination experiments}

Combination and dose reduction index. The ratio of the tested compounds used in the combinations, specified by their Dm values and also by the preliminary results (data not shown) provided the fraction of not viable cells $(\mathrm{Fa})$ in the range of 0 to 1 . Six to eight concentrations of each compound, in the range of $0.125 \times \mathrm{Dm}$ to $6 \times \mathrm{Dm}$ in a constant ratio at 2 -fold dilution series according to recommendation given by Chou (24) were used in combination experiments. Combination index values $(\mathrm{CI})$ were generated in CalcuSyn Software at $\mathrm{ED}_{50}, \mathrm{ED}_{75}$ and $\mathrm{ED}_{90}$ after fitting Fa values obtained by MTTbased assay (Table II). As it is important to reduce toxicity in clinical treatment and 5-FU is an essential component of chemotherapy in acute lymphoblastic leukemia (ALL) and breast cancer commonly used in consolidation therapy, dose reduction index (DRI) values are shown for tested combinations. The obtained CI values for CCRF-CEM were in the range of 0.52 to 1.79 with the lowest Dm for 5-FU:TBBi. However, the best synergistic effect with $\mathrm{CI}$ values in the range of 0.52-0.81 (synergism/moderate synergism) was achieved for the 5-FU:2b combination and DRI for 5-FU was equal to 20.6 at $\mathrm{Fa}=0.95$. The obtained data indicated, that the dose of 5-FU may be decreased about 20 -fold at $95 \%$ of leukemia cells affected, when it is in a combination with 2 b derivative. For 5FU:CX4945 combination, the synergistic interaction was observed only in MCF-7 cells with CI values in the range of 0.62-0.92 indicating synergism/light synergism. The quite different combination scenario was clearly observed in CCRFCEM cells for CX-4945 plus 5-FU combination, and in MCF7 cells for 5-FU and TBBi, where antagonism occurred. Representative examples of the graphs generated from the analysis of two compound combinations, demonstrating the synergistic effect, i.e., CX-494 plus 5-FU and for CX-4945 plus $2 \mathrm{~b}$ in both cell lines are shown in Figure 1.

Induction of apoptosis of CCRF-CEM leukemia cells. In order to explain the observed synergism of 5-FU and $2 \mathrm{~b}$, induction of apoptosis in CCRF-CEM was studied. Due to a strong synergism of the 5-FU: $2 \mathrm{~b}$ combination used for CCRF-CEM treatment, concentrations of $15 \mu \mathrm{M}$ and $30 \mu \mathrm{M}$ 

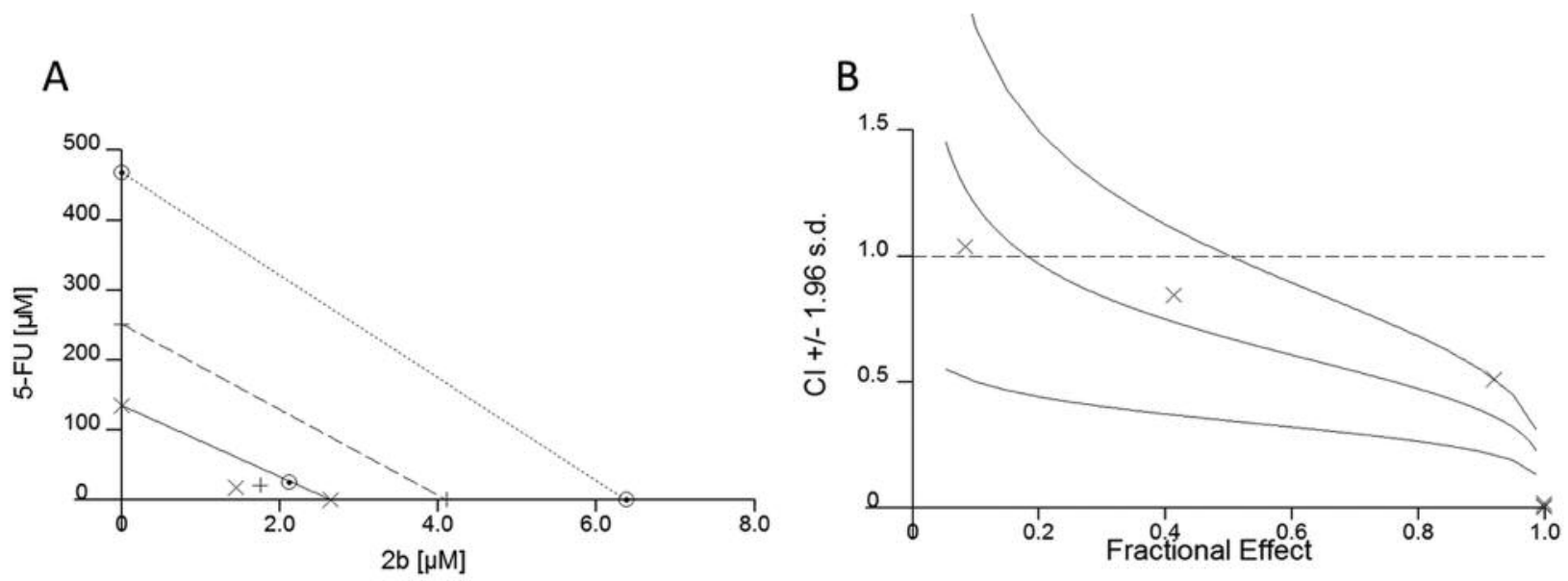

XED50 +ED75 $\quad$ EDD90
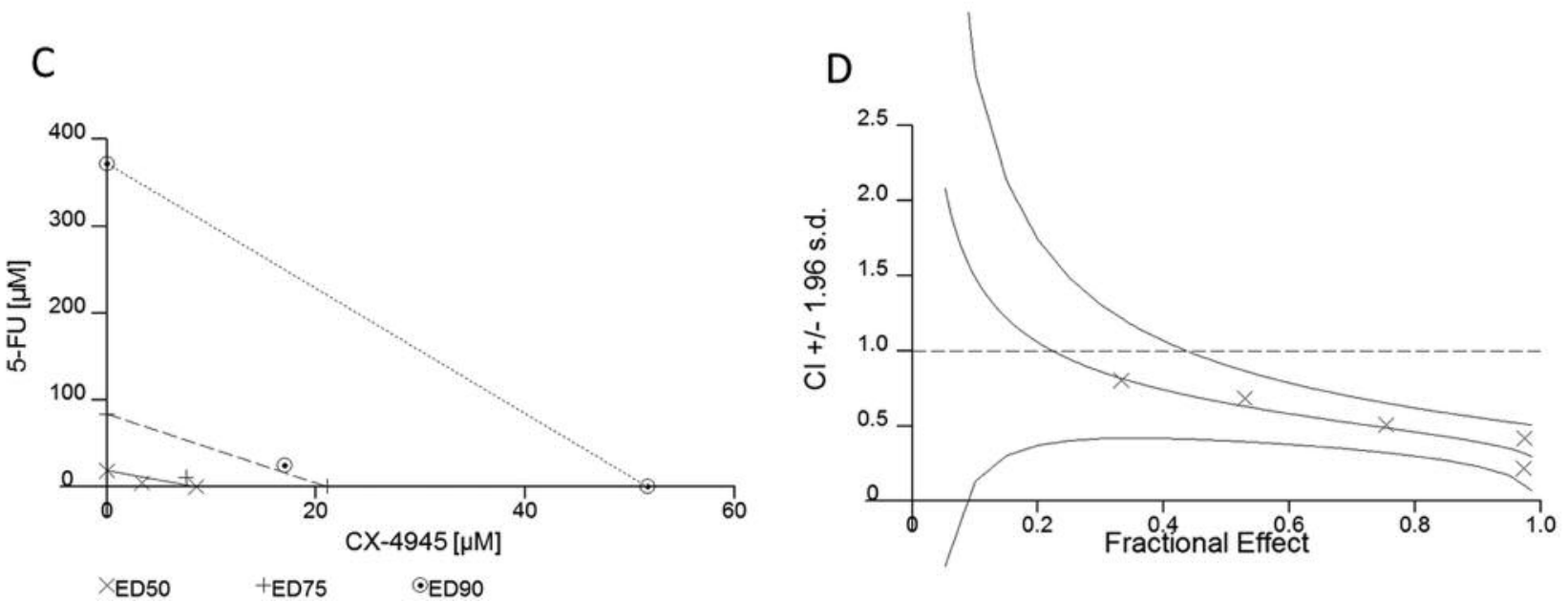

Figure 1. Synergistic interaction of 5-FU with $2 b$ or CX-4945 in inhibition of viability of CCRF-CEM (A, B) and MCF-7 (C, D). Representative CalcuSyn software-simulated isobolograms $(A, C)$ and Fa-CI curves $(B, D)$, generated after fitting Fa obtained from the MTT assay.

5-FU, corresponding to $0.125 \mathrm{Dm}$ and $0.25 \mathrm{Dm}$, respectively, and $3 \mu \mathrm{M} 2 \mathrm{~b}$ were used in this assay. The results, showing a pro-apoptotic influence of the tested compounds used separately or in two combinations are shown in Figure 2. The treatment of the leukemia cells with the combinations of $15 \mu \mathrm{M}$ or $30 \mu \mathrm{M} 5$-FU with $2 \mathrm{~b}$, resulted in $57.1 \%$ and $70.1 \%$ total apoptotic cells, respectively. Treatment with $15 \mu \mathrm{M}$ 5-FU, $30 \mu \mathrm{M} 5-\mathrm{FU}$ or $3 \mu \mathrm{M} 2 \mathrm{~b}$ separately resulted in $10.9 \%$, $18.2 \%$ and $14.9 \%$ total apoptotic cells. The obtained data indicated synergistic effect of both combinations of 5-FU and $2 \mathrm{~b}$ on induction of apoptosis and are in a good agreement with the MTT-based drug combination results.

The effect of the synergistically acting combinations on a cell cycle progression in CCRF-CEM and MCF-7 cell lines. Since, it has been shown by others that CX-4945 (2), as well as 5-FU
(25), can affect cell-cycle progression of leukemia and breast cancer cells, the influence of 5 -FU in combination with $2 \mathrm{~b}$ or CX-4945 on cell cycle progression was tested after 48 and 72 $\mathrm{h}$ treatment of CCRF-CEM and MCF-7 cells. Concentrations of 5-FU used in this experiment varied in the range of 0.125 and $0.7 \mathrm{Dm}$ depending on the cell line (due to strong synergism in CCRF-CEM cells $15 \mu \mathrm{M}$ and $30 \mu \mathrm{M}$ 5-FU, corresponding to 0.125 and $0.25 \mathrm{Dm}$, respectively, were used, while for MCF7 cells $5 \mu \mathrm{M}$ and $10 \mu \mathrm{M} 5$-FU, corresponding to 0.3 and 0.7 Dm, respectively, were used). Inhibitors of CK2, 2b and CX4945 were used at $3 \mu \mathrm{M}$ and $4 \mu \mathrm{M}$ concentrations, respectively. The cell-cycle distribution profiles after treatment with each compound used separately and with two compound combinations were determined by flow cytometry. The representative plots with the calculations of cell percentages in each phase of the cell cycle are shown in Figure 3. 


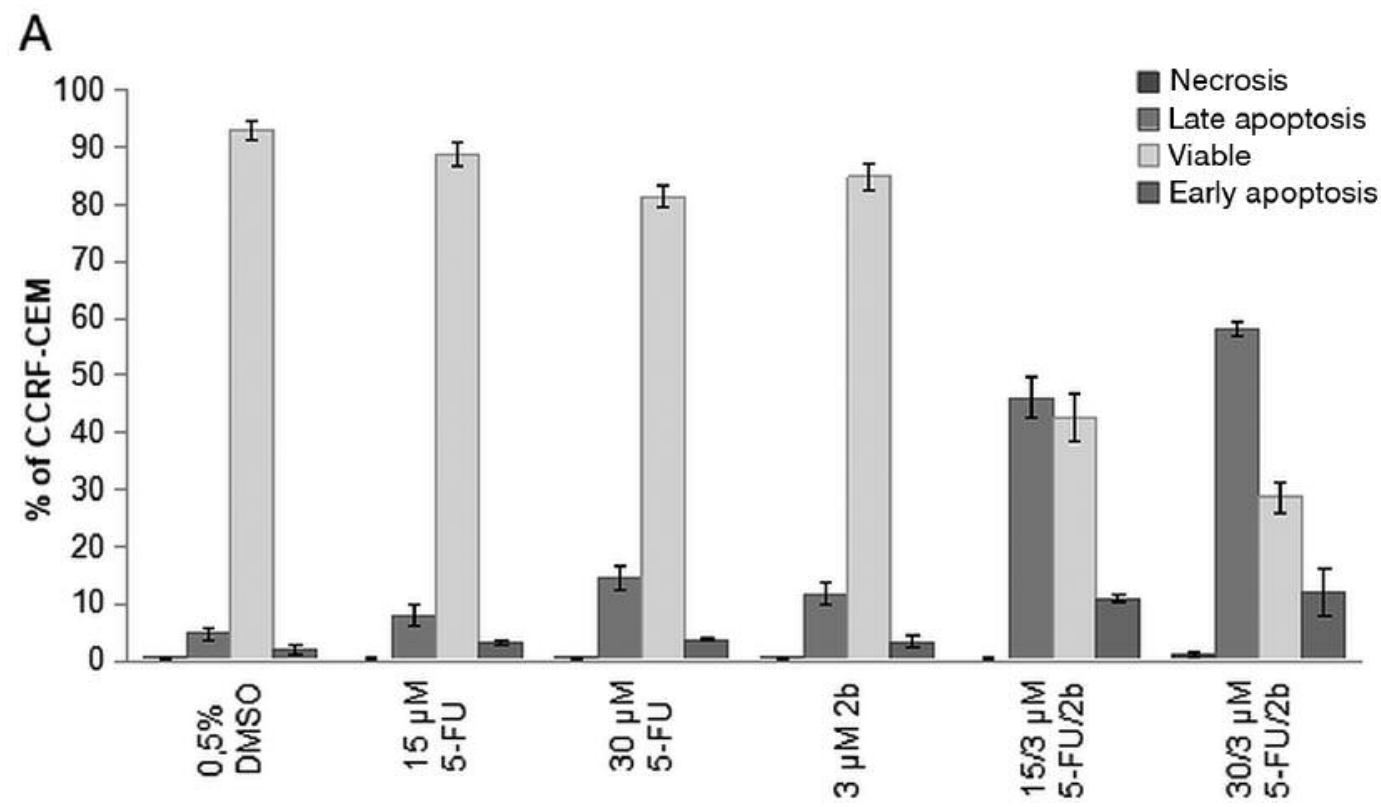

B

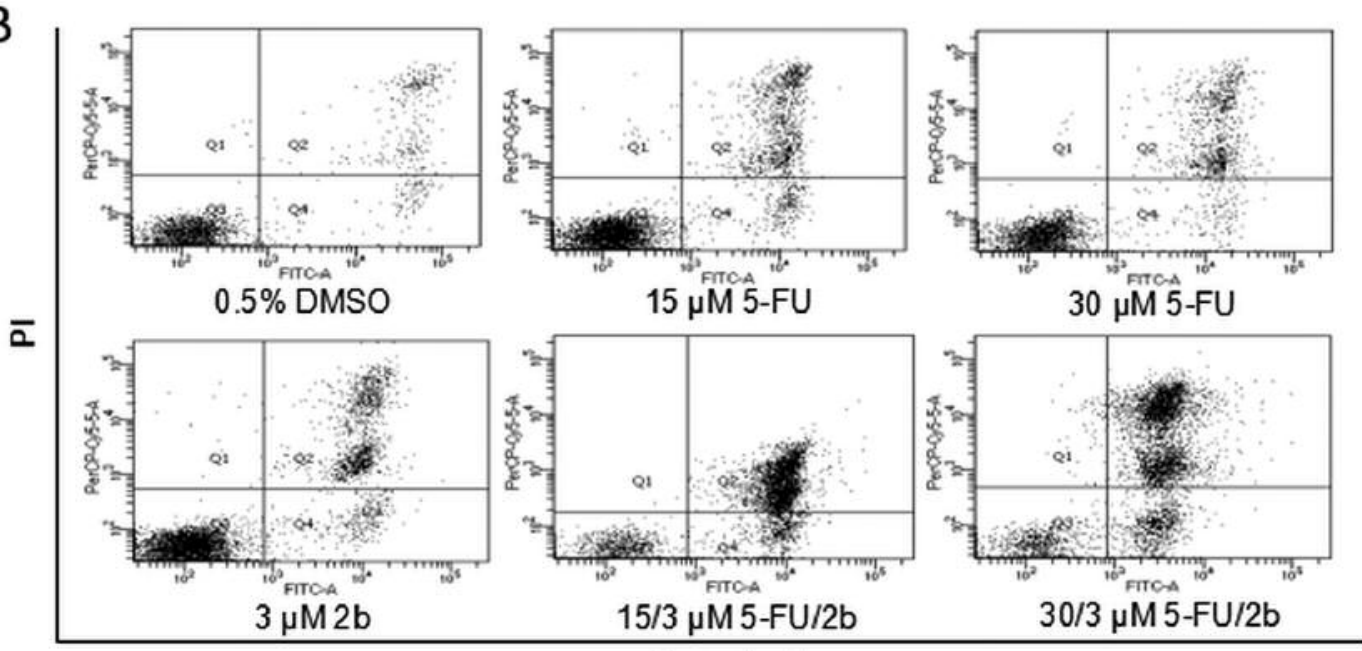

Annexin V

Figure 2. Pro-apoptotic and anti-leukemic activity of 5-FU and 2b, when used separately or in combination. The data were acquired by FACS cytometer after $72 \mathrm{~h}$ treatment. Cells were stained with annexin V-FITC and PI. (A) Mean and standard deviation (SD) of total apoptosis as percent from three independent experiments each. (B) Representative graphs for: control (0.5\% DMSO), $15 \mu M$ 5-FU, $30 \mu M 5-F U, 3 \mu M 2 b$ and combinations of 5-FU (15 and $30 \mu \mathrm{M})$ and $2 b$, respectively.

The obtained results indicated that 5-FU led to S-phase arrest in both studied cell lines. The number of cells in S-phase correlated with the time of the treatment in MCF-7 cells, with the strongest effect leading to $41 \%$ more cells in $\mathrm{S}$ phase at 10 $\mu \mathrm{M} 5$-FU after $72 \mathrm{~h}$ treatment than in control cells. In contrary, although the treatment of MCF-7 cells with $4 \mu \mathrm{M}$ CX-4945 alone led to S-phase accumulation (43\%) after 48 h, G2/M arrest occurred (13\% more cells, than in control) after $72 \mathrm{~h}$. Interestingly, the observed effect of 5-FU:CX4945 combination in both concentrations seems to unblock the CX-4945 induced $\mathrm{G}_{2} / \mathrm{M}$-phase arrest in MCF-7 cells after $72 \mathrm{~h}$ treatment, leading to $12 \%$ and $9 \%$ less cells in this phase. Additionally, the recovery from S-phase arrest induced by 5-FU in both concentrations occurred after the combined treatment with 5FU: CX-4945 for $72 \mathrm{~h}$. However, 5-FU:CX4945 combination at $10 \mu \mathrm{M}: 4 \mu \mathrm{M}$ concentrations delayed replication recovery, leading to $17 \%$ more cells in S-phase relatively to control cells after $72 \mathrm{~h}$ than after $48 \mathrm{~h}$ treatment. 

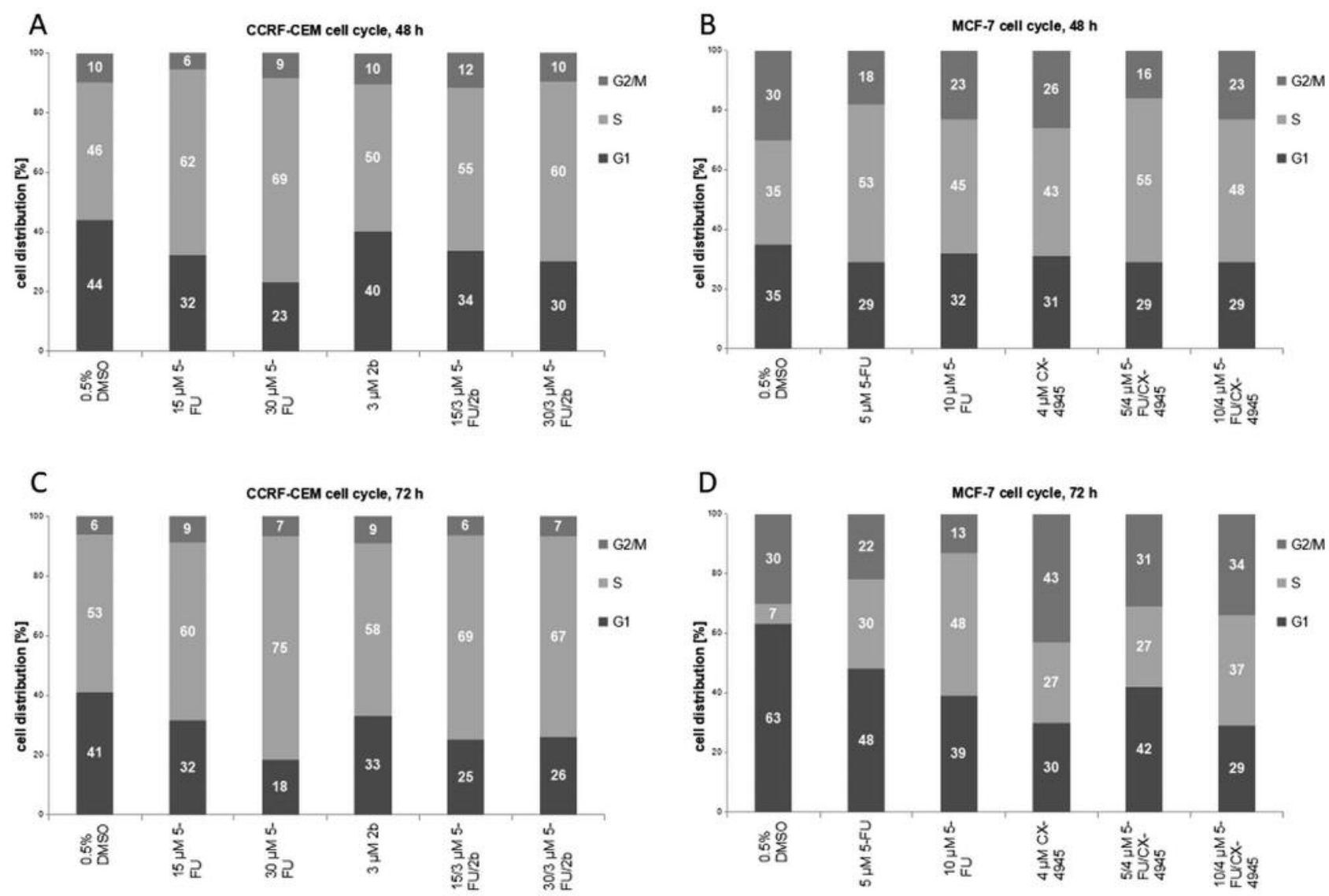

Figure 3. The effect of compound combinations on a cell-cycle progression in CCRF-CEM and MCF-7 cell lines. CCRF-CEM cells were treated with 5-FU and $2 b$ used separately or in combination for $48 h(A)$ or $72 h(C), M C F-7$ cells were treated with 5-FU and CX-4945 used separately or in combination for $48 h(B)$ or $72 h(D)$, and then fixed and stained with PI. The cell cycle distribution profiles of the cells were determined by flow cytometry. Representative graphs indicate the percentages of cells in the $G_{1}, S$ and $G_{2} / M$ phases of the cell cycle.

TBBi derivative $2 \mathrm{~b}$ at $3 \mu \mathrm{M}$ concentration induced S-phase arrest in CCRF-CEM after $48 \mathrm{~h}$ treatment, but to a lesser extent than CX-4945 in MCF-7 and did not induce $\mathrm{G}_{2} / \mathrm{M}$ arrest. However, the similar recovery from 5-FU induced $\mathrm{S}$ phase arrest was observed after 5-FU:2b combination treatment for $48 \mathrm{~h}$ and $72 \mathrm{~h}$ incubation time, as it was observed in MCF-7 after $72 \mathrm{~h}$ treatment with 5-FU:CX4945 (both combinations).

The effect of simultaneous inhibition of TS and CK2 on TS, $C K 2 \alpha$, and total p65 protein levels and p65 phosphorylation. In view of the observations that TS protein level increased after inhibition of protein catalytic activity contributed to the inefficiency of chemotherapy (26), we checked the influence of 5-FU, 2b and CX-4945 used separately, and in combinations on the level of TS and CK2 $\alpha$ proteins in cellular extracts obtained from both cell lines. The complex of TS with 5-fluoro-dUMP was detected in CCRF-CEM and MCF-7 cell lines (Figure 4B and D, the upper line) after 5-FU treatment, as well as after treatment with combination of 5-FU with either $2 \mathrm{~b}$ or CX-4945. Consequently, near 1.6-fold increase of TS protein level, compared to control cells, was observed after treatment with 5 -FU and its combination with $2 \mathrm{~b}$ in leukemia cells (Figure 4A and B) and about 3-fold and 3.5-fold increase of TS protein level after treatment with $5-\mathrm{FU}$ and its combination with CX-4945 in MCF-7 cells, respectively (Figure $4 \mathrm{C}$ and D). Interestingly, whereas compound $2 \mathrm{~b}$ decreased the TS level in CCRF-CEM (Figure $4 \mathrm{~A}$ and B), almost 2-fold increase of TS level was observed after CX4945 treatment in MCF-7 (Figure 4 C and D). Additionally, the endocellular inhibition of CK2 was studied by assaying p65 (NF-kB factor) serine 529 phosphorylation. Inhibition of CK2 activity was detected in leukemia cells after treatment with $2 \mathrm{~b}$ (68.5\% phosphorylation of $\mathrm{p} 65$ versus control), whereas after combination treatment with 5-FU 

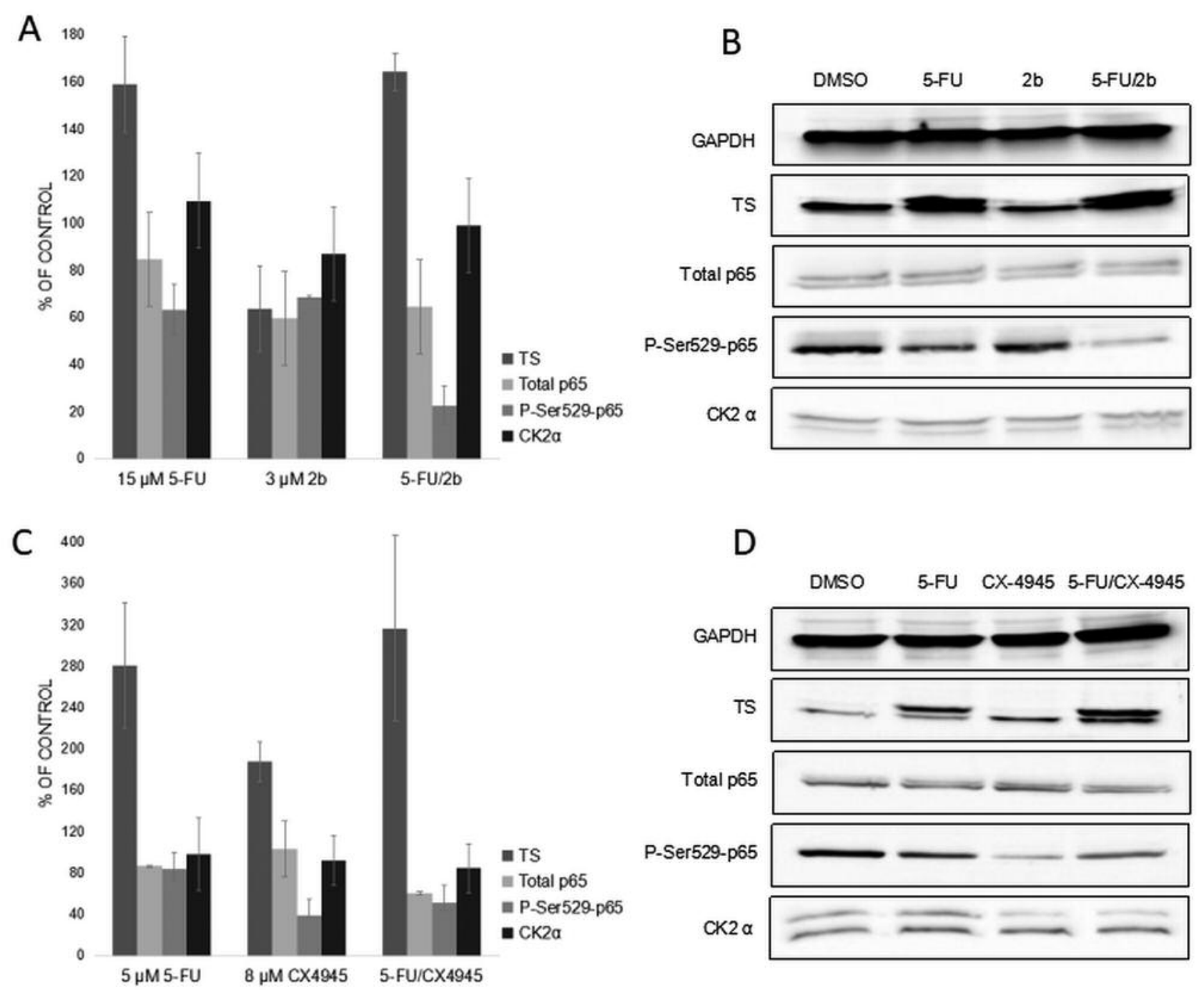

Figure 4. Western blot analysis of TS, CK2 $\alpha$, total p65 and P-Ser529-p65 in the crude extracts obtained from CCRF-CEM (A, B) or MCF-7 (C, D) after $72 \mathrm{~h}$ treatment with 5-FU and $2 b$ (CCRF-CEM) and 5-FU and CX-4945 (MCF-7), used separately or in combinations. $40 \mu \mathrm{g}$ extract (in RIPA buffer) was loading per well. P-Ser529-p65 (NF-kB factor) was used as a marker of cellular inhibition of CK2. GAPDH was used as a loading control for each sample. Densitometry quantifications for each protein are shown in the graphs $(A, C)$ with untreated cells serving as the reference point (100\%), and the representative blots $(B, D)$ are shown for CCRF-CEM and MCF-7, respectively. Preparation of cell extracts and protein detection is described in the Materials and Methods Section.

and $2 \mathrm{~b}$ phosphorylation of $\mathrm{p} 65$ reached only $22.7 \%$, indicating a synergistic mechanism. As, no essential influence on $\mathrm{CK} 2 \alpha$ protein level was observed after treatment with $2 \mathrm{~b}$ or its combination, the decreased level of phosphorylated Ser529-p65 is due to inhibition of CK2 activity. In contrary, in MCF-7 cells the combination treatment of 5-FU and CX-4945 did not show a similar synergistic effect, as inhibition of CK2 after the combined treatment was even lower (51\% of phosphorylated p65) than after CX-4945 treatment (39\% of phosphorylated p65).

\section{Discussion}

The effect of inhibitors directed against two different molecular targets, i.e. protein kinase CK2 and TS, used alone or in combination, was studied on leukemia and breast cancer cells. Our results demonstrated that the effects of $5-\mathrm{FU}, 2 \mathrm{~b}$ and CX4945 used in combination was depended on the type of cell line. Interestingly, 5-FU:CX-4945 affected the viability of cells in a synergistic manner only in MCF-7 cell line, whereas 5-FU:2b resulted in synergism only in CCRF-CEM cell line. It has been 
shown by others, that drug interaction effect may be dependent on both cell line and concentration ratio $(11,27)$ and a combination of anti-casein kinase 2 CIGB-300 peptide and 5FU provided antagonistic interaction in both the NCI-H125 lung cancer cell line and in the SiHa cervical cancer cell line (27). The obtained synergistic effect in CCRF-CEM after combination treatment with 5-FU and TBBi derivative $2 \mathrm{~b}$ seems to be correlated with stronger inhibition of CK2 and consequently with increase in the pro-apoptotic activity. It has been shown that $\mathrm{CK} 2$ and its substrates such as kinase Akt protect cells from apoptosis by phosphorylating a wide range of proteins involved in the apoptotic response $(28,29)$ and consequently inhibition of CK2 leads to increase apoptosis in many types of cancer cells, including leukemia (7). The increase in the pro-apoptotic activity of 5-FU and $2 \mathrm{~b}$ combination could not influence MCF-7 cells, taking into account that this line demonstrates caspase-3 deficiency and consequently undergoes cell death that lacked typical apoptotic properties (30).

The accumulation of cells in S-phase, that occurred in both studied cell lines after $48 \mathrm{~h}$ and $72 \mathrm{~h} \mathrm{5-FU} \mathrm{treatment,}$ indicates the initiation of repair mechanisms (17), induced by DNA damage. By contrast to CCRF-CEM, the synergistic effect occurring in MCF-7 after simultaneous CX-4945 and 5-FU treatment, seems to be related to the delay of 5-FUinduced S-phase arrest recovery, leading to $17 \%$ more cells in S-phase versus control after $72 \mathrm{~h}$, compared to $48 \mathrm{~h}$ treatment. The obtained results can be partially correlated to DNA repair mechanisms, as it was shown by others that CX4945 blocks the DNA repair response induced by gemcitabine and cisplatin in ovarian cancer cells (11). It was demonstrated that phosphorylation of a key mediator of homologous recombination double strand break (DSB) repair MDC1 by CK2 (23) is necessary for the formation of a multiprotein complex, that is required for DSB repair signaling (31). Taking into account that DNA damage is an essential mechanism of cytotoxicity of 5-FU in different cell lines, and DSB induction exhibited a significant correlation with sensitivity of MCF-7 to 5-FU (22), inhibition of CK2 leading to block DNA repair, after 5-FU treatment seems to be a very likely mechanism of a synergistic interaction between 5-FU and CX-4945.

The $\mathrm{G}_{2} / \mathrm{M}$ arrest that occurred in MCF-7 after CX-4945 treatment is in a good agreement with the literature data, showing that cell-cycle regulation by $\mathrm{CK} 2$ is cell type dependent and CX-4945 treatment induced different effect on cell cycle progression in BT-474 breast cancer and nonNSCLC -small cell lung cancer, BxPC-3 pancreatic cancer and leukemia stem cells, causing an arrest in $G_{2} / M, G_{1}$ or in the late $S-G_{2}-M$ phases of the cell cycle, respectively $(5,32$, 33). It was demonstrated that treatment of cells with CX4945 resulted in reduced phosphorylation of a key cell-cycle inhibitor protein, p21 (T145) and increased the stability and levels of total p21 and p27 (34).
We detected increased levels of TS protein after 5-FU treatment in both studied cell lines with a higher value of $281 \%$ over the control in MCF-7 cell line. It was demonstrated that the clinical use of TS inhibitors is limited by the emerging tumor resistance which is caused by increased TS protein level. Among the mechanisms leading to the rise of TS levels are reduced turnover and increased stability of the protein in the presence of enzyme-inhibitor complexes, and the up-regulation of TS expression $(35,36)$. The increase in TS expression occurring during 5-FU chemotherapy is associated with an autoregulatory mechanism of translation control for the enzyme (36). Ligand-free TS protein binds its own mRNA and thereby represses translation $(38,39)$. Complex formation with the dUMP substrate or inhibitors, including FdUMP, abolishes mRNA binding of TS (40). Therefore, increased levels of TS expression are observed during chemotherapy with 5-FU despite inactivation of the enzyme, which ultimately results in emergence of tumor cells resistance. Many studies demonstrated that combination treatment of 5-FU with other agents such as paclitaxel or cisplatin is a promising regimen that is well tolerated in patients with advanced gastric cancer (41-43). Other studies showed, that combination of rapamycin (inhibitor of mTOR protein kinase) and pemetrexed (folate antimetabolite, inhibitor of thymidylate biosynthesis cycle enzymes) synergistically inhibits in vivo proliferation of non-small cell lung cancer (NSCLC) xenografts via decreasing mTOR activity and pemetrexedinduced TS expression (44). Our studies indicated almost 2fold increase in TS levels in MCF-7 cells after CX-4945 treatment and 3-fold increase of TS levels after combined treatment with 5-FU. The observed effect at about $60 \%$ of CK2 inhibition seems to be in a good agreement with previous studies, demonstrating the influence of phosphorylation of TS on both catalytic and non-catalytic properties of the enzyme. It has been demonstrated by Luo (13) that phosphorylated TS is stabilized in an inactive conformation. Other studies indicated that phosphorylation of TS increased its binding to its own mRNA, causing a negative regulation of translation (14). Therefore, consequently inhibition of TS phosphorylation should lead to increased levels of TS protein in cells. By contrast to CX45945, a TBBi derivative, $2 \mathrm{~b}$, induced a decrease of the TS levels to $64 \%$ of control in CCRF-CEM cell line. However, after combined treatment with 5-FU, the TS levels were similar to that observed after 5-FU used separately. The lack of increase of TS levels after $2 b$ treatment in CCRF-CEM can be related to a lower extent of CK2 inhibition to about $30 \%$, in comparison to inhibition of CK2 in MCF-7, although, both inhibitors were used in concentrations close to their Dm values, representing the summary effect of the inhibitor on viability of cells of each line (MTT assay). Therefore, differences in the selectivity of the tested 
inhibitors should be taken into account. Interestingly, a decrease of p65 subunit of nuclear factor-kappa B (NF-kB) phosphorylation (Ser529) indicating CK2 inhibition in CCRF-CEM after 5-FU treatment was observed, whereas in MCF-7 p65 total and p65-P-Ser529 were only slightly decreased in compare to control. Recently, it was demonstrated that activation of NF-kB protected colon cancer cells against therapy-induced cytotoxicity (45) and consequently, suppressing PI3K/AKT and NF-kB/iNOS signaling pathways by melatonin synergized the chemotherapeutic effect of 5-FU in colon cancer (19).

In summary, the obtained results indicated that inhibitors of TS may have a better therapeutic effect when combined with a drug that exerts a CK2-inhibitory effect. However, the interaction mechanism can be different and depends on cancer cell line and drug combination. Moreover, taking into account that increase of TS protein levels could contribute to chemo-resistance, further studies need to be performed.

\section{Acknowledgements}

This research was supported by National Science Centre (Poland) grant nr 2014/13/B/NZ7/02273 and by Warsaw University of Technology.

\section{References}

1 Łukowska-Chojnacka E, Wińska P, Wielechowska M, Poprzeczko $M$ and Bretner $\mathrm{M}$ : Synthesis of novel polybrominated benzimidazole derivatives - potential CK2 inhibitors with anticancer and proapoptotic activity. Bioorg Med Chem 24: 735$741,2016$.

2 Gray GK, McFarland BC, Rowse AL, Gibson SA and Benveniste EN: Therapeutic CK2 inhibition attenuates diverse prosurvival signaling cascades and decreases cell viability in human breast cancer cells. Oncotarget 5: 6484-6496, 2014.

3 Prins RC, Burke RT, Tyner JW, Druker BJ, Loriaux MM and Spurgeon SE: CX-4945, a selective inhibitor of casein kinase-2 (CK2), exhibits anti-tumor activity in hematologic malignancies including enhanced activity in chronic lymphocytic leukemia when combined with fludarabine and inhibitors of the B-cell receptor pathway. Leukemia 27: 2094-2096, 2013.

4 Buontempo F, McCubrey JA, Orsini E, Ruzzene M, Cappellini A, Lonetti A, Evangelisti C, Chiarini F, Evangelisti C, Barata JT and Martelli AM: Therapeutic targeting of CK2 in acute and chronic leukemias. Leukemia 32: 1-10, 2018.

5 Siddiqui-Jain A, Drygin D, Streiner N, Chua P, Pierre F, O'Brien SE, Bliesath J, Omori M, Huser N, Ho C, Proffitt C, Schwaebe MK, Ryckman DM, Rice WG and Anderes K: CX- 4945, an orally bioavailable selective inhibitor of protein kinase CK2, inhibits prosurvival and angiogenic signaling and exhibits antitumor efficacy. Cancer Res 70: 10288-10298, 2010.

6 Guerra B and Issinger OG: Protein kinase CK2 in human diseases. Curr Med Chem 15: 1870-1886, 2008.

7 Chon HJ, Bae KJ, Lee Y and Kim J: The casein kinase 2 inhibitor, CX-4945, as an anti-cancer drug in treatment of human haematological malignancies. Front Pharmacol 6: 1-5, 2015.
8 Piazza F, Manni S, Ruzzene M, Pinna LA, Gurrieri C and Semenzato G: Protein kinase CK2 in hematologic malignancies: reliance on a pivotal cell survival regulator by oncogenic signaling pathways. Leukemia 26: 1174-1179, 2012.

9 Buontempo F, Orsini E, Lonetti A, Cappellini A, Chiarini F, Evangelisti C, Evangelisti C, Melchionda F, Pession A, Bertaina A, Locatelli F, Bertacchini J, Neri LM, McCubrey JA and Martelli AM: Synergistic cytotoxic effects of bortezomib and CK2 inhibitor CX-4945 in acute lymphoblastic leukemia: turning off the prosurvival ER chaperone BIP/Grp78 and turning on the pro-apoptotic NF-kB. Oncotarget 7: 1323-1340, 2016.

10 Jung JI, Park KY, Kim SA and Kim J: Synergistic therapeutic effect of diethylstilbestrol and CX-4945 in human acute T-lymphocytic leukemia cells. Biomed Pharmacother 98: 357-363, 2018.

11 Siddiqui-Jain A, Bliesath J, Macalino D, Omori M, Huser N, Streiner N, Ho CB, Anderes K, Proffitt C, O’Brien SE, Lim JK, Von Hoff DD, Ryckman DM, Rice WG and Drygin D: CK2 inhibitor CX-4945 suppresses DNA repair response triggered by DNA targeted anticancer drugs and augments efficacy: mechanistic rationale for drug combination therapy. Mol Cancer Ther 11: 994-1005, 2012.

12 Frączyk T, Kubiński K, Masłyk M, Cieśla J, Hellman U, Shugar D and Rode W: Phosphorylation of thymidylate synthase from various sources by human protein kinase CK2 and its catalytic subunits. Bioorg Chem 38: 124-131, 2010.

13 Luo BB, Repalli J, Yousef AM, Johnson SR, Lebioda L and Berger SH: Human thymidylate synthase with loop 181-197 stabilized in an inactive conformation: Ligand interactions, phosphorylation, and inhibition profiles. Protein Sci 20: 87-94, 2011.

14 Frączyk T, Ruman T, Rut D, Dąbrowska-Maś E, Cieśla J, Zieliński Z, Sieczka K, Dębski J, Gołos B, Wińska P, WałajtysRode E, Shugar D and Rode W: Histidine phosphorylation, or tyrosine nitration, affect thymidylate synthase properties. Pteridines 20: 137-142, 2009.

15 Chu E, Callender MA, Farrell MP and Schmitz JC: Thymidylate synthase inhibitors as anticancer agents: from bench to bedside. Cancer Chemother Pharmacol 52: 80-89, 2003.

16 Haddad R, Colevas AD, Tishle R, Busse P, Goguen L, Sullivan C, Norris CM, Lake-Willcutt B, Case MA, Costello R and Posner M: Docetaxel, cisplatin, and 5-fluorouracil-based induction chemotherapy in patients with locally advanced squamous cell carcinoma of the head and neck. Cancer 97: 412-418, 2003.

17 Longley DB, Harkin DP and Johnston PG: 5-Fluorouracil: mechanisms of action and clinical strategies. Nat Rev Cancer 3: 330-338, 2003.

18 Rich TA, Shepard RC and Mosley ST: Four decades of continuing innovation with fluorouracil: current and future approaches to fluorouracil chemoradiation therapy. J Clin Oncol 22: 2214-2232, 2004.

19 Gao Y, Xiao X, Zhang C, Yu W, Guo W, Zhang Z, Li Z, Feng X, Hao J, Zhang K, Xiao B, Chen M, Huang W, Xiong S, Wu $\mathrm{X}$ and Deng W: Melatonin synergizes the chemotherapeutic effect of 5-fluorouracil in colon cancer by suppressing $\mathrm{PI} 3 \mathrm{~K} / \mathrm{AKT}$ and NF-kB/iNOS signaling pathways. J Pineal Res 62: 1-15, 2017.

20 Saleh EM, El-Awady RA and Anis N: Predictive markers for the response to 5-fluorouracil therapy in cancer cells: Constant-field gel electrophoresis as a tool for prediction of response to 5fluorouracil-based chemotherapy. Oncol Letters 5: 321-327, 2013. 
21 Li LS, Morales JC, Veigl M, Sedwick D, Greer S, Meyers M, Wagner M, Fishel R and Boothman DA: DNA mismatch repair (MMR)-dependent 5-fluorouracil cytotoxicity and the potential for new therapeutic targets. Br J Pharmacol 158: 679-692, 2009.

22 VanTriest B, Pinedo HM, Giaccone G and Peters GJ: Downstream molecular determinants of response to 5-fluorouracil and antifolate thymidylate synthase inhibitors. Ann Oncol 11: 385-391, 2000.

23 Becherel OJ, Jakob B, Cherry AL, Gueven N, Fusser M, Kijas AW, Peng C, Katyal S, McKinnon PJ, Chen J, Epe B, Smerdon SJ, Taucher-Scholz G and Lavin MF: CK2 phosphorylationdependent interaction between aprataxin and MDC1 in the DNA damage response. Nucleic Acids Res 38: 1489-503, 2010.

24 Chou TC: Theoretical basis, experimental design, and computerized simulation of synergism and antagonism in drug combination studies. Pharmacol Rev 58: 621-681, 2006.

25 Johnston PG, Drake JC, Trepel J and Allegra CJ: Immunological quantitation of thymidylate synthase using the monoclonal antibody TS 106 in 5-fluorouracil-sensitive and -resistant human cancer cell lines. Cancer Res 52: 4306-4312,1992.

26 Brunn ND, Dibrov SM, Kao MB, Ghassemian M and Hermann T: Analysis of mRNA recognition by human thymidylate synthase. Biosci Rep 34: 905-913, 2014.

27 Perera Y, Del Toro N, Gorovaya L, De-Cossio JF, Farina HG and Perea SE: Synergistic interactions of the anti casein kinase 2 CIGB 300 peptide and chemotherapeutic agents in lung and cervical preclinical cancer models. Mol Clin Oncol 2: 935-944, 2014.

28 Izeradjene K, Douglas L, Delaney A and Houghton JA: Casein kinase II (CK2) enhances death-inducing signaling complex (DISC) activity in TRAIL-induced apoptosis in human colon carcinoma cell lines. Oncogene 24: 2050-2058, 2005.

29 Ribeiro ST, Tesio M, Ribot JC, Macintyre E, Barata JT and Silva-Santos B: Casein kinase 2 controls the survival of normal thymic and leukemic $\gamma \delta \mathrm{T}$ cells via promotion of AKT signalling. Leukemia 31: 1603-1610, 2017.

30 Wang S, He M, Li L, Liang Z, Zou Z and Tao A: Cell-in-cell death is not restricted by caspase-3 deficiency in MCF-7 cells. J Breast Cancer 19: 231-241, 2016.

31 Chapman JR and Jackson SP: Phospho-dependent interactions between NBS1 and MDC1 mediate chromatin retention of the MRN complex at sites of DNA damage. EMBO 9: 795-801, 2008.

32 Quotti Tubi L, Canovas Nunes S, Brancalion A, Doriguzzi Breatta E, Manni S, Mandato E, Zaffino F, Macaccaro P, Carrino M, Gianesin K, Trentin L, Binotto G, Zambello R, Semenzato $\mathrm{G}$, Gurrieri C and Piazza F: Protein kinase CK2 regulates AKT, NF-kB and STAT3 activation, stem cell viability and proliferation in acute myeloid leukemia. Leukemia 31: 292-300, 2017.

33 So KS, Rho JK, Choi YJ, Kim SY, Choi CM, Chun YJ, and Lee JC: Akt/mTOR down-regulation by CX-4945, a CK2 inhibitor, promotes apoptosis in chemorefractory non-small cell lung cancer cells. Anticancer Research 35: 1537-1542, 2015.

$34 \mathrm{Li}$ Y, Dowbenko D and Lasky LA: AKT/PKB phosphorylation of $\mathrm{p} 21 \mathrm{Cip} / \mathrm{WAF} 1$ enhances protein stability of $\mathrm{p} 21^{\mathrm{Cip} / \mathrm{WAF} 1}$ and promotes cell survival. J Biol Chem 277: 11352-11361, 2002.
35 Scartozzi M, Maccaroni E, Giampieri R, Pistelli M, Bittoni A, Del Prete M, Berardi $R$ and Cascinu S: 5-Fluorouracil pharmacogenomics: still rocking after all these years? Pharmacogenomics 12: 251-265, 2011.

36 Kitchens ME, Forsthoefel AM, Rafique Z, Spencer HT and Berger FG: Ligand-mediated induction of thymidylate synthase occurs by enzyme stabilization. Implications for autoregulation of translation. J Biol Chem 274: 12544-12547, 1999.

$37 \mathrm{Chu}$ E and Allegra CJ: Mechanisms of clinical resistance to 5fluorouracil chemotherapy. Cancer Treat Res 87: 175-195, 1996.

38 Chu E, Voeller D, Koeller DM, Drake JC, Takimoto CH, Maley GF and Allegra CJ: Identification of an RNA binding site for human thymidylate synthase. Proc. Natl Acad Sci USA 90: 517$521,1993$.

39 Lin X, Parsels LA, Voeller DM, Allegra CJ, Maley GF, Maley F and Chu E: Characterization of a cis-acting regulatory element in the protein coding region of thymidylate synthase mRNA. Nucleic Acids Res 28: 1381-1389, 2000.

40 Tai N, Schmitz JC, Liu J, Lin X, Bailly M, Chen TM and Chu E: Translational autoregulation of thymidylate synthase and dihydrofolate reductase. Front Biosci 9: 2521-2526, 2004.

41 Hwang J, Cho SH, Shim HJ, Lee SR, Ahn JS, Yang DH, Kim YK, Lee JJ, Kim HJ and Chung IJ: Phase II study of paclitaxel, cisplatin, and 5-fluorouracil combination chemotherapy in patients with advanced gastric cancer. J Korean Med Sci 23: 586-591, 2008.

42 Murad AM, Petroianu A, Guimaraes RC, Aragao BC, Cabral LO and Scalabrini-Neto AO: Phase II trial of the combination of paclitaxel and 5-fluorouracil in the treatment of advanced gastric cancer - a novel, safe, and effective regimen. Am J Clin Oncol 22: 580-586, 1999.

43 Kim YH, Shin SW, Kim BS, Kim JH, Kim JG, Mok YJ, Kim CS, Rhyu HS, Hyun JH and Kim JS: Paclitaxel, 5-fluorouracil, and cisplatin combination chemotherapy for the treatment of advanced gastric carcinoma. Cancer 85: 295-301, 1999.

44 Kawabata S, Chiang CT, Tsurutani J, Shiga H, Arwood ML, Komiya T, Gills JJ, Regan MM and Dennis PA: Rapamycin downregulates thymidylate synthase and potentiates the activity of pemetrexed in non-small cell lung cancer. Oncotarget 5: 1062$1070,2014$.

45 Körber MI, Staribacher A, Ratzenböck I, Steger G and Mader RM: NFkB-Associated pathways in progression of chemoresistance to 5-fluorouracil in an in vitro model of colonic carcinoma. Anticancer Res 36: 1631-1639, 2016.
Received June 13, 2018

Revised July 6, 2018

Accepted July 10, 2018 